\title{
Programas educativos de negocios: una perspectiva holística
}

Neftali Parga Montoya

\section{Resumen}

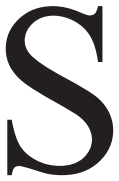
e revisan los efectos que ha tenido la pandemia por Covid-19 sobre los modelos educativos relacionados con los negocios. Se propone la fijación de la gestión participativa en una perspectiva holística que incluye la pluralidad de los actores principales, los escenarios territoriales y/u organizacionales. La educación superior en la colectividad, valores y actitudes que consienten la funcionalidad humana. Pensar y actuar como principios de una profesión con compromiso colectivo y visión humanista.

Palabras clave: programa educativo, negocios, áreas de oportunidad, licenciatura, visión humanista.

\section{Introducción}

El año 2020 se caracterizó por delimitar la función de la empresa en acciones particulares que promueven su eficiencia: económica y simbólica. El confinamiento dispuso una experiencia real sobre las necesidades prioritarias que tiene la sociedad y, en este sentido, a las organizaciones que ponen a su disposición los bienes y servicios demandados. La comercialización cara a cara representó para las organizaciones un obstáculo amargo sobre el máximo control del comercio; esta situación pone un cuestionamiento válido sobre las instituciones de educación superior (IES) públicas que tienen dentro de su oferta educativa planes de estudio relacionados con negocios: ¿cuál es el valor que tienen los programas educativos de negocios? Es evidente que existe una fuerte tendencia por parte de las IES (principalmente privadas) para poner entre su haber programas educativos relacionados con negocios, esto debido a la cada vez más redundante orientación del mercado a través de una empresa que, en este sentido, las IES se comprometen a satisfacer esa demanda laboral. La notable industrialización que quedó expuesta por no corresponder a las exigencias de una sociedad en pandemia dejó entrever las carencias que no sólo a nivel industrial se tenían, sino también a nivel educativo en la preparación de los individuos que se ciernen en los negocios en su entorno económico y social.
El éxito de las IES se circunscribe en la continuidad de evaluar los programas educativos para formar a nuevos individuos que se relacionarán con las empresas del futuro. Las universidades estaban incrustadas en un ambiente de oportunidades de negocio en cadenas de valor tradicionales que combinaban industrias con fuerzas como la globalización, la innovación tecnológica y la comercialización local (Peters et al., 2018). El paso obligado al mercadeo digital del sector empresarial exige al nuevo estudiante y a su mentor de negocios repensar su enseñanza universitaria bajo las condiciones actuales, a fin de no ser un ejemplo tácito de la falta de adaptación schumpeteriana $^{1}$ (por ejemplo, como la empresa Kodak, a principios de siglo, tomando el viraje digital demasiado tarde [Barabba, 2011]). Sin embargo, fiarse de la perspectiva innovadora, la mayoría de las veces, encubre las condiciones fundamentales que deben ser tomadas en cuenta para una vocación humana. Las consecuencias devastadoras en derechos laborales y humanos se vieron amenazados por empujar a la sociedad hacia una mayor inseguridad e incertidumbre (International Labour Organization, 2020).

1 Schumpeteriano, condición de un individuo, organización o economía que se inclina hacia una postura marginal de innovación (Berume and Epitalon, 2009). 


\section{La formación educativa en temas de negocios}

En los últimos años, la educación en temas de negocios se ha centrado principalmente en casos de estudio y sus cambios hacia las nuevas generaciones. Especialmente, aleccionar en cuanto el valor del trabajo sin contar necesidades puntuales del individuo: planes de retiro, provisión de servicios de salud y/o pago justo. Los mensajes continuos son de tomar nota a la volatilidad, incertidumbre, complejidad y ambigüedad del nuevo mundo. Esta visión estática de la organización tradicional que prioriza el rendimiento sobre la persona ha sido debatida por la misma industria, siendo ahora que, las mismas empresas más importantes del mundo dejan la vieja usanza y adoptan la postura relajada de compañías de tecnología, negocios por internet, social media, juegos y nichos de menudeo en el que se combinan nuevas formas de producir. Aunque, hoy en día, las formas de prepararse son mayores (cursos en línea, capacitaciones extraoficiales y diplomados a distancia, entre otros), la educación en temas de negocios, sobre todo en la IES pública, sigue teniendo como base ese tronco convencional sin inclinarse a los modelos disruptivos que demanda el mercado laboral (Peters et al., 2018).

Las acreditadoras internacionales de IES en el ámbito de los negocios ponen clara la orientación del trabajo pedagógico en sus misiones: Impact, Innovation et Engagement (Impacto, Innovación y Compromiso) (AACSB, 2021; EFMD Global, 2021). La pandemia es una llamada de atención y un punto de no retorno para revalorar la experiencia académica en el que se tienda a enfrentar con mayor inercia los cambios educacionales de la IEs. Sin excepción, el punto de quiebre está en un análisis de la cadena de valor actual para el estudiante de negocios: conocimientos, habilidades, experiencias y programas, entre otros. No obstante, para las IES dar las herramientas de actualización conlleva tomar en cuenta los nuevos entrantes como la tecnología, contenido a distancia, disposición de la enseñanza y democratización de la educación; aspectos que han sido adoptados por la educación privada en modalidades cortas que atienden las necesidades del estudiante de negocios con sistemas de evaluación ad hoc a la industria, sin tener que pasar a la preparación formal, aunque sí, más selectiva con su mercado estudiantil con bases en el mérito, tiene el mismo objetivo de instruir de manera tecnicista. Por ejemplo, las empresas Walmart, Intel o Bank of America tienen muy en cuenta la selección de personal, cuando han tomado la instrucción de sus propios sistemas educativos. El año pasado, Google
《La pandemia es una llamada de atención

y un punto de no retorno para revalorar la

experiencia académica en el que se tienda

a enfrentar con mayor inercia los cambios educacionales de la IES $\gg$

se incluyó a esta lista, ofreciendo sus propios "títulos académicos" retando a la enseñanza convencional, con certificaciones profesionales de seis meses para reforzar las competencias laborales, "con la misma validez que un grado de cuatro años" (García, 2020).

La inclusión de las empresas en el rubro educativo cambia las reglas del juego, como juez y parte del mercado laboral, atendiendo a las características de puestos concretos, demandados y de alta remuneración. Las características de los títulos universitarios entran a ser competencia de alta calidad, bajos costos y tiempos cortos de formación con una tendencia clara de una tecnicidad reclamada. Esto es, motu proprio, cambiar la educación superior a una simple técnica que transfiere el conocimiento hacia la consigna de la productividad. En este entorno educativo, donde la IES representa rigidez, prórroga y sobrecualificación, se debe obrar en consecuencia para corregir la formación hacia el modelo educativo que cuestione las prácticas mecanicistas de la dexteridad. El mercado laboral se debe nutrir de competencias pluridisciplinarias que acompañen a la gente real en su vivencia diaria con aprendizajes en las diversas dimensiones humanas (solidaridad, intercambio, inclusividad, entre otros). La pandemia por COVID-19 y su estruendoso efecto en la deshumanización de la industria para no albergar a millones de trabajadores en situaciones vulnerables, nos muestra la amenaza latente de lo que se percibe actualmente como un "negocio".

Vale revindicar los sentimientos morales que Adam Smith publicó hace doscientos años para colocar al sujeto económico en el lugar del otro, aun cuando no se obtenga beneficio de ello (Smith, 1822). La fragilidad de los lazos que componen una sociedad constituyen su fuerza y su capacidad de integración (Taddei et al., 2021). La evolución de la educación superior está en la colectividad, valores $\mathrm{y}$ actitudes que consienten la funcionalidad humana en la apertura tecnológica, adaptados al despliegue rápido del trabajo colaborativo. La pandemia por Covid-19 reestructura la organización social de vuelta al sujeto, donde se vierte ya no sólo la pertinencia económica, sino también la social y ecológica. Un programa educativo de negocios debe partir de la gestión participativa que lleva a la acción en un aprendizaje que considere los siguientes aspectos: 


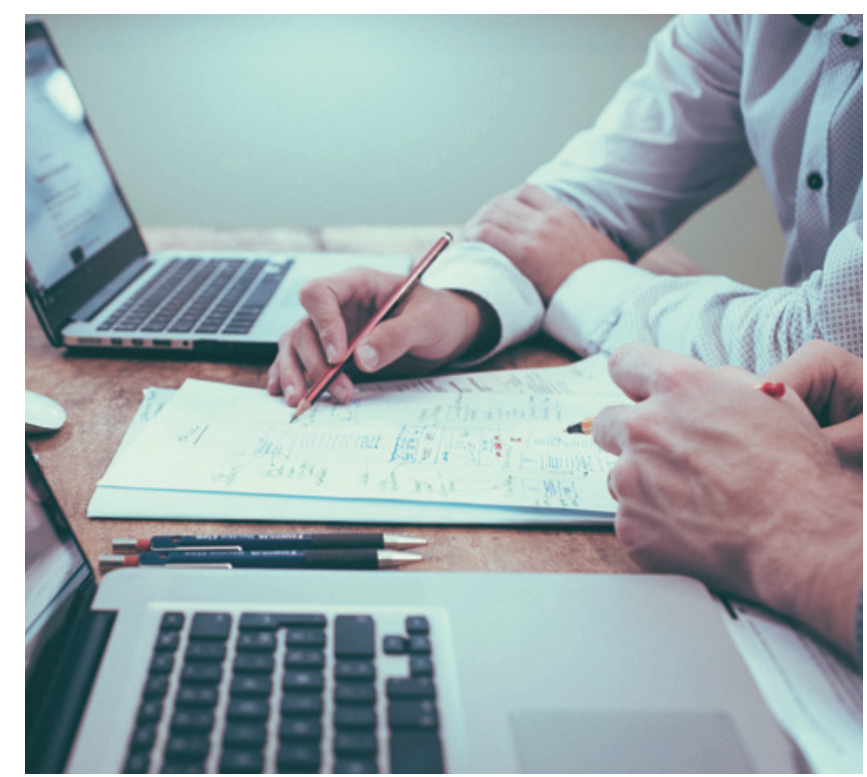

1) el conocimiento de los roles de los poderes públicos a diferentes escalas; 2) la comprensión de la organización pública y privada; 3) la identificación de los problemas actuales en movilidad, alimentación, tecnologías de información, producción y distribución de los bienes de consumo; 4) así como los retos económicos, ambientales, sociales y territoriales de las actividades económicas (de Carlo, 2020).

De esta forma, los estudiantes aprenden que la problematización de un tema en específico tiene una escala holística de situaciones territoriales $\mathrm{y} / \mathrm{u}$ organizacionales que trabaja con una pluralidad de actores (Lorino, 2020). Se propone así, dentro de la orientación académica del estudiante universitario, considerar herramientas metodológicas que tengan como objetivo principal: "aprender a aprender”. En un carácter tubular y disciplinario de competencias transversales y diversificadas para la gestión participativa (Danvers, 2009). Una estrategia para desarrollar la orientación educativa que construye la participación en el educando es la modularización integral de contenidos disciplinarios: cursos de formación que redondean la preparación de las competencias disciplinarias y profesionales (por ejemplo, Université de Paris, 2021 o Université Paul-Valéry Montpellier 3, 2021, Université de Toulon, 2021). De esta forma, se crean cursos más individualizados y particulares para las exigencias de cada individuo desde su proyecto personal, profesional y social. Se favorecen y revalorizan contenidos que construyen competencias de trabajo en equipo, investigación, uso de herramientas tecnológicas y aprendizajes asociativos a la carrera profesional (Dardel et al., 2017), que no son solamente conocimientos y habilidades técnicas, sino ma- terias fundamentales para la cimentación del perfil crítico cultural, económico y ambiental (Tiona y Eboue, 2019).

\section{Conclusiones}

La realidad de la IES post-pandemia por COVID-19 se presenta en un Leviatán, una situación de grandes dimensiones difícil de controlar, que se manifiesta en crisis financieras, sociales y ecológicas. Estuvimos acostumbrados al escenario ideal de un mundo conectado con mayores libertades de movilidad. Las cadenas de suministro eran "estables" y "eficaces", ahora, la sacudida nos depone los paradigmas en la cara para revisitar los asuntos clave del nuevo ambiente. Es bien entendido que la innovación deberá continuar, pero, no solamente a escala empresarial. La empresa no existe sin una vida política, social o ambiental, y su desempeño financiero es indisoluble del desempeño que no es financiero. Las posturas actuales también se remueven para dominar las múltiples disciplinas con métodos y ángulos de análisis que lleven al cuestionamiento crítico y reflexivo en una gestión de negocios participativa. La discordancia entre el discurso enfático y los actos insuficientes para contribuir al entorno de los programas educativos se reflejan en la actitud que nuestros alumnos adoptan hacia el modelo educativo. En este texto se discurre que la orientación que fomente la acción y la autonomía de aprendizajes sobre el estudiante desde la construcción de su propio conocimiento por módulos ayudará a proporcionar flexibilidad a las actividades pedagógicas que le dan sentido a su profesión en un ámbito social que no dejaría de ser especializado; a fin de lograr lo que conviene al individuo y al grupo social al que pertenece con una sensibilización del entorno en el que vive y reflexión de la obligación social de su próximo oficio (Dardel et al., 2017).

El papel de las IES es proveer las herramientas para que los actores educativos favorezcan la vida universitaria y profesional de nuestros estudiantes fuera de posturas meritocráticas (Duru-Bellat, 2021). En ese contexto, nuestro trabajo de enseñanza debe generar la ocasión para compartir su curiosidad e inquietudes en el entorno global y local. Otorgarles las condiciones para pensar y actuar con otros actores en el marco de sus profesiones futuras en favor de la transición económica, social y ecológica. La experiencia del compromiso colectivo y la perspectiva de actuar profesionalmente no inician en la tecnicidad, sino en el conocimiento imprescindible de la visión humanista que como individuos debemos tener. Como Kant (1784) 
señaló, la educación es el bien universal, el arte que nos lleva a la ilustración del género humano. La educación representa disciplina e instrucción, aunque también tiene la preocupación fundamental de dar espacio para la igualdad, la libertad y la perfección humana en el desarrollo moral del pensamiento y la conducta del individuo en beneficio de los demás (Lafuente-Guantes, 2009).
《La experiencia del compromiso colectivo y

la perspectiva de actuar profesionalmente no inician en la tecnicidad, sino en el conocimiento imprescindible de la visión humanista que como individuos debemos tener $\gg$

\section{Fuentes de consulta}

AACSB. (2021). History of AACSB. [Página web]. Consultada el 11 de mayo de 2021, en https://www.aacsb.edu/about/ who-we-are/timeline

Barabba, V. (2011). Decision Loom. Triarchy press.

Berume, S. \& Epitalon, G. (2009). Una contribución schumpeteriana a la gestión de la innovación en materia de recursos humanos. Contaduría y Administración, (228), 129-149.

Danvers, F. (2009). S'orienter Dans La Vie: Une Valeur Suprême?: Dictionnaire de Sciences Humaines, 1126. Presses Universitaires Septentrion.

Dardel, F. Jeanneret, M.-H. \& Petipré, M. (2017). Licence, PACES, APB: pourquoi le système coince? Comment le faire évoluer? The Conversation. France. Consultado en http://bitly.ws/hztK

De Carlo, L. (2020). Management: enseigner l'action collective pour la transition écologique, The Conversation. Francia. Consultado en http://bitly.ws/hztF

Duru-Bellat, M. (2021). Le mérite est-il encore un idéal démocratique? The Conversation, France. Consultado en http:// bitly.ws/hztS

EFMD. (2021). About us. [Página web]. Consultada en http://bitly.ws/hztX

García, J. (2020). Google, también [va] por las universidades: crea sus propias titulaciones por 250 euros. El País. Madrid. Consultado en http://bitly.ws/hzu2

International Labour Organization. (2020). Issue Paper on COVID-19 and Fundamental Principles and Rights at Work. Ginebra. Consultado en http://bitly.ws/hzu5

Kant, I. (1784). ¿Qué es la Ilustración? Edición de Rodrigo R. Aramayo. Filosofía de la historia. Alianza Editorial.

Lafuente-Guantes, M. (2009). El Proyecto Educativo-Ilustrado de Kant. Revista Historia de la Educación Latinoamericana. 13(13), 241-264. Colombia: Universidad Pedagógica y Tecnológica de Colombia.

Lorino, P. (2020). Pragmatisme: le management participatif. Pragmatisme et Étude Des Organisations-Philippe Lorino. Francia: Université de Lorraine. [Video]. Consultado en https://videos.univ-lorraine.fr/index.php?act=view\&id_ col=625

Peters, K., Smith, R. R. \& Thomas, H. (2018). Rethinking the Business Models of Business Schools: A Critical Review and Change Agenda for the Future. Reino Unido: Emerald Publishing.

Smith, A. (1822). The Theory of Moral Sentiments. [Sexta edición]. Escocia. Penguin Random House LLC.

Taddei, F., Mainguy, G. \& Naves, M.-C. (2021). Débat: Célébrer l'éducation et les apprentissages, un combat universel. The Conversation. Francia. Consultado en https://theconversation.com/debat-celebrer-leducation-et-les-apprentissages-un-combat-universel-153466

Tiona, J. \& Eboue, R. (2019). Éducation sociétale et responsable: mythes et réalités en milieu de l'enseignement secondaire technique et professionnel au Cameroun. Éd. OEconomia (Clermont-Ferrand) Université de Paris. (2021). Du PaRéO - Passeport pour Réussir et s'Orienter. [Página web]. Consultada en https://orientationactive.uparis.fr/du-pareo/\#1449239942203-82c1d00b-b2d0

Université de Toulon. (2021). Création du D.U. 'Passeport pour réussir et s'orienter' (Du PaRéO). [Página web]. Consultada en http://bitly.ws/hzua

Université Paul-Valéry Montpellier 3. (2021). Passeport pour réussir et s'orienter-Diplôme d'université. [Página web]. Consultada en https://www.univ-montp3.fr/fr/pareo 